\title{
GENDER DIFFERENCE ON MENTAL HEALTH IN STUDENTS DURING COVID-19 PANDEMIC
}

\author{
Muna Maimunah Salsabila
}

Masters Program in Public Health, Universitas Sebelas Maret

\begin{abstract}
Background: COVID-19 pandemic was negatively affected mental health in college students across the world. It brings uncertainty regarding academic success, future careers, and social life during college, amongst other concerns. Studies exploring adolescents' responses to pandemic have generally found poorer mental health for some sub-groups following the event, such as gender. However, such findings are not consistent across the literature. The purpose of this study was to investigate gender difference on mental health in students during COVID-19 pandemic.

Subjects and Method: A systematic literature search was conducted in multiple databases including PubMed, Google Scholar, Scopus, and complemented by crossreferencing to identify cross-sectional study published from 2020 to 2021 . The following search terms were used: "Mental Health" OR Mental Health Disorders OR Psychological Impact) AND (College Students OR University Students) AND Pandemic COVID-19. The inclusion criteria were English full text and randomized controlled trial. The articles were filtered using PICO model, including: (1) Population= college students, (2) intervention $=$ female, (3) comparison $=$ male, and (4) outcome $=$ mental health disorder. The inclusion criteria were English full-text and reported adjusted odds ratio (aOR). The systematic review was carried out according to the PRISMA flowchart. Data analysis were performed using RevMan 5.3.

Results: A meta-analysis included 9 studies involving 88,058 students from China, Egypt, France, Pakistan, Ethiopia, and Bangladesh. This study found that female students had higher risk on mental health disorder than male students during COVID19 pandemic $(\mathrm{aOR}=1.66 ; 95 \% \mathrm{CI}=1.29$ to 2.13 ; $\mathrm{p}<0.001)$.
\end{abstract}

Conclusion: Female students have higher risk on mental health disorder than male students during COVID-19 pandemic.

Keywords: mental health, psychological impact, college students, COVID-19, gender

\section{Correspondence:}

Muna Maimunah Salsabila. Masters Program in Public Health, Universitas Sebelas Maret. Jl. Ir. Sutami 36A, Surakarta 57126, Central Java. Email: munamaimunahs@gmail.com. Mobile: +6285728565926 . 